\title{
Optimization of the Chitinase Production by Different Metarhizium anisopliae Strains under Solid-State Fermentation with Silkworm Chrysalis as Substrate Using CCRD
}

\author{
Cynthia Barbosa Rustiguel, João Atílio Jorge, Luis Henrique Souza Guimarães* \\ Department of Biology, Faculdade de Filosofia, Ciências e Letras de Ribeirão Preto, \\ Universidade de São Paulo, São Paulo, Brazil \\ Email: *1hguimaraes@ffclrp.usp.br
}

Received April 20, 2012; revised May 30, 2012; accepted June 7, 2012

\begin{abstract}
Entomopathogenic fungi, such as Metarhizium anisopliae, are able to control various insect pests. These fungi attack the integument of the host using an enzymatic complex. Among the enzymes found in this complex, chitinase is an important component. However, the relation between the chitinase production and the virulence from different $M$. anisopliae strains has not been analyzed. In this manuscript it is presented the chitinase production by four $M$. anisopliae strains with different potential of virulence in Solid-State Fermentation using silkworm chrysalis as substrate. The higher chitinase level was obtained with the strain IBCB 360 (7.14 U/g of substrate) with potential virulence of $68 \%$ on Diatrea saccharalis. The enzyme production was optimized for all strains using a factorial planning (CCRD) considering the cultivation time and medium humidity as independent variables. The maximal production of chitinase was obtained at a range from 8 to 12 -days old cultures and from $45 \%$ to $62 \%$ of moisture according to the surface response plot, with high $\mathrm{R}^{2}$ value. The enzyme production by the strain IBCB 167 was increased two-folds under optimized conditions, while for the strains IBCB 360 and 425 the chitinase production was increased four-folds and nine-folds for the strain IBCB 384.
\end{abstract}

Keywords: Entomopathogenic Fungus; Metarhizium anisopliae; Chitinase; Solid-State Fermentation

\section{Introduction}

The entomopathogenic fungi are pathogens with a broadspectrum of action which are able to attack insects that live in different ecological niches in different stages of development. Most of these species are specialized in penetrating the tegument [1]. The interaction between pathogen and host is influenced by different factors such as enzymes production, environment temperature and humidity, light and ultraviolet radiation, as well as by nutritional conditions and host susceptibility. Thus, the complete cycle of infection involves the sequential stages of adhesion, germination, appressorium formation, formation of staple penetration, penetration, colonization and reproduction of the pathogen in the insect [1]. Enzymes play an important role during the penetration of the fungus in the host, especially during adhesion and germination which occurs at the germ tube formation, releasing enzymes that degrade the cuticle of the insect as, for example, proteases and chitinases, among others

"Corresponding author.
[2]. Some studies have discussed the relation between the production of enzymes with pathogenicity and virulence [3-5]. The entomopathogenic fungus Metarhizium anisopliae is a deuteromycete from Monoliaceae family widely distributed in the nature that can be easily found in the soil. This fungus has been studied due to its ability to control insect pests [1,6,7]. Zappelini (2009) [8] analyzed different strains of the entomopathogenic fungi Beauveria bassiana and $M$. anisopliae to verify their potential of infection and mortality on Diatrea saccharalis and it was observed that the virulence from each one of the 27 M. anisopliae strains analyzed was variable. The strain IBCB 167, for example, was able to kill around $55 \%$ of D. saccharalis while the strains IBCB 360 , IBCB384 and IBCB 425 showed a mortality power of $68 \%-90 \%$. These different values can be attributed to the enzymatic complex associated to the virulence, including chitinase.

Chitinases (EC 3.2.1.14) are enzymes widely spread in nature that can be found in a great diversity of organisms, with special attention to the filamentous fungi. Chitinase catalyzes the hydrolysis of chitin, an insoluble linear 
molecule constituted by $\mathrm{N}$-acetyl glucosamine units linked by $\beta-1,4$ (GlcNAc) linking [9] found in insect cuticle. The complete hydrolysis of chitin occurs through a chitinolytic system which acts synergistically and consecutively [10]. Chitinases are divided into two main classes, the endochitinases and the exochitinases. The endochitinases cleave chitin at random sites within the polymer, releasing chito-oligosaccharides (chitotetraose, chitotriose). The exochitinases cleave chitin from its non-reducing end, releasing dimers (GlcNAc) 2 [11,12]. These enzymes have multiple biological roles as, for example, in the infection of insects by entomopathogenic fungi. According to Boldo et al. (2009) [5], M. anisopliae produces different chitinases related to the infection process on the host. However, the relation between the level of chitinase production by different strains of $M$. anisopliae and their virulence has not been analyzed. Hence, this manuscript presents the production of chitinase by the strains IBCB 167, IBCB 360, IBCB384 and IBCB 425 from $M$. anisopliae with different virulence potential and the optimization of enzyme production by factorial design (CCRD).

\section{Material and Methods}

\subsection{Microorganisms}

Four different strains (IBCB 167, 360, 384 and 425) from M. anisopliae classified according to their virulence potential and deposited in the Collection of Entomopathogenic Microorganisms "Oldemar Cardim Abreu" from the Laboratory of Biological Control, Biological Institute of Campinas, São Paulo, Brazil were used. The strains were maintained on PDA (potato dextrose agar) slants and stored at $4^{\circ} \mathrm{C}$ in refrigerator. Spores from 15 days-old cultures were used to obtain new cultures, which were initially maintained at $25^{\circ} \mathrm{C}$ for 7 days and then stored at $4^{\circ} \mathrm{C}$.

\subsection{Obtainment of Cultures under Solid-State Fermentation (SSF) and Crude Extract}

The cultures under SSF were obtained by inoculating of $1 \mathrm{~mL}$ of a spore suspension $\left(10^{5}\right.$ spores $\left./ \mathrm{mL}\right)$ on $4 \mathrm{~g}$ of crushed dry chrysalis from silkworm (BRATAC S.A., Brazil) (Figure 1) as substrate/carbon source moistened with tap water, yeast extract solution $(1 \% \mathrm{~m} / \mathrm{V})$, SR salt solution [20×] [13] or Khanna salt solution [14], previously autoclaved at $120^{\circ} \mathrm{C}, 1.5 \mathrm{~atm}$ for 30 minutes. The cultures were maintained in a stove at $26^{\circ} \mathrm{C}$ for different periods (96 - 312 hours) with relative humidity around $76 \%$ monitored by a thermo hygrometer.

After incubation, the cultures were added with $50 \mathrm{~mL}$ of cold distilled water previously autoclaved in the same conditions cited above, maintained under agitation for 1

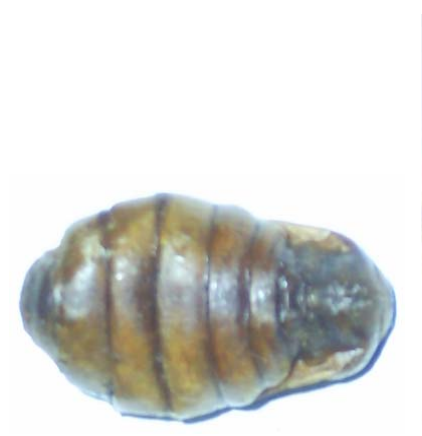

(a)

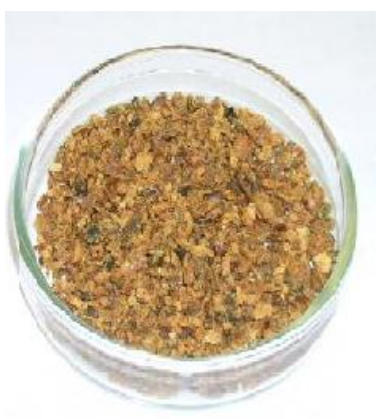

(b)
Figure 1. Pictures from intact chrysalis (a) and triturated chrysalis (b) from silkworm used as substrate for chitinase production by different strains from $M$. anisopliae under SSF.

$\mathrm{h}$ and harvested by gauze using Whatman paper No.1. The free cell filtrate, identified as extracellular crude extract, was dialyzed against distilled water at $4^{\circ} \mathrm{C}$ overnight and used for chitinase activity determination.

\subsection{Determination of the Chitinase Activity}

The determination of the chitinase activity was accomplished using $1 \mathrm{mM}$ of the synthetic substrate 4-Nitrophenyl N-acetyl- $\beta$-D glucosaminide $\left(\right.$ Sigma $\left.^{\circledR}\right)$ in $100 \mathrm{mM}$ sodium acetate buffer, $\mathrm{pH}$ 5.0. The reaction was performed using $200 \mu \mathrm{L}$ of the substrate solution and 200 $\mu \mathrm{L}$ of the enzymatic sample. After incubation at $60^{\circ} \mathrm{C}$, the reaction was stopped at different time intervals by adding $1 \mathrm{~mL}$ of $1 \mathrm{M} \mathrm{NaOH}$. All experiments were performed in triplicate. The $p$-nitrophenolate released was quantified at $\lambda=405 \mathrm{~nm}$ in a spectrophotometer. One unit of enzyme activity (U) was defined as the amount of enzyme required to hydrolyze $1 \mu \mathrm{mol}$ of substrate per minute under the assay conditions.

\subsection{Optimization of the Enzyme Production}

The optimization of enzyme production for all M. anisopliae strains under SSF was carried out using a factorial design $\left(2^{2}\right)(\mathrm{CCRD})$, where the independent variables were the time of growth (X) and humidity (Y). These parameters were chosen because the microbial growth and, consequently, the enzyme production are drastically influenced by the culture conditions, including water activity and cultivation time, among others. The temperature was maintained at $26^{\circ} \mathrm{C}$ since the influence of this variable is a well characterized parameter for $M$. anisopliae growth. Three repetitions were performed at the central points $(0)$ and two outer points $(-1.41,+1.41)$ were considered, totalizing 11 trials (Table 1). The results were subjected to analysis of variance (ANOVA) with $p$ values of 0.05 and 0.1 using the software Statis- 
tica 8.0 (Stat Soft). Values lower than the $p$ values fixed were considered statistically significant. The Pareto charts and surface response graphs were obtained using the same software. The equations that describe de model for the influence of each independent variable on the enzymatic production were obtained using the same software and validated by the experimental results using the best conditions of cultivation time ( 9 days-old cultures) and humidity (48\%).

\section{Results and Discussion}

\subsection{Influence of Salt Solution on the Enzyme Production in SSF}

The availability of the nutrients and salts is an important factor to the growth of microorganisms and, consequently to the enzyme production. In Table 2 , the influence of different salt solutions (tap water, yeast extract solution, SR and Khanna salt solutions) on chitinase production under SSF by $M$. anisopliae strains can be observed. Higher levels of chitinase were obtained when the substrate silkworm chrysalis was moistened with yeast extract $(1 \%)$ at the ratio 1.3:1 $(\mathrm{m} / \mathrm{V})$ for the strains IBCB 167, 360 and 425, differing than that observed for the strain IBCB 384 with best enzyme production when the substrate was moistened with Khanna salt solution

Table 1. Encoded and real values for both independent variables time of growth and medium humidity used for factorial design (CCRD) to evaluate the chitinase production by four strains of $M$. anisopliae under SSF using silkworm chrysalis as substrate.

\begin{tabular}{|c|c|c|c|c|c|c|}
\hline & Encoded values & -1.41 & -1.0 & 0 & +1.0 & +1.41 \\
\hline \multirow{2}{*}{ 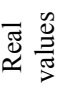 } & Time of growth (days) & 4 & 5 & 9 & 12 & 13 \\
\hline & Medium humidity (\%) & 23 & 30 & 48 & 65 & 72 \\
\hline
\end{tabular}

The encoded axial points were calculated using $\left(2^{\mathrm{k}}\right)^{1 / 4}$, where $\mathrm{k}$ is the number of independent variables in the study.

Table 2. Influence of different salt solutions, tap water and solution of yeast extract in the production of chitinases by different isolates of the fungus $M$. anisopliae in SSF.

\begin{tabular}{ccccc}
\hline \multicolumn{5}{c}{ Extracellular chitinase activity $(\mathrm{U} / \mathrm{g}$ substrate) } \\
\hline Solution & 167 & 360 & 384 & 425 \\
Tap water & $0.73 \pm 0.01$ & $0.87 \pm 0.01$ & $0.35 \pm 0.01$ & $1.09 \pm 0.01$ \\
$\begin{array}{c}\text { Yeast extract } \\
\text { solution }\end{array}$ & $2.42 \pm 0.05$ & $1.76 \pm 0.03$ & $0.30 \pm 0.01$ & $1.33 \pm 0.01$ \\
$\begin{array}{c}\text { SR salt } \\
\text { solution }\end{array}$ & $0.63 \pm 0.01$ & $0.71 \pm 0.01$ & $0.20 \pm 0.01$ & $0.84 \pm 0.01$ \\
$\begin{array}{c}\text { Khanna salt } \\
\text { solution }\end{array}$ & $0.62 \pm 0.01$ & $0.72 \pm 0.01$ & $0.46 \pm 0.01$ & $0.85 \pm 0.00$ \\
\hline
\end{tabular}

The cultures were kept at $26^{\circ} \mathrm{C}$ with relative humidity of around $76 \%$ for a period of 168 hours.
$(1.3: 1 \mathrm{~m} / \mathrm{V})$. The solution of yeast extract has soluble proteins, amino acids, biotin and it is rich in B complex vitamins [15]. Amino acids are absorbed and utilized in cellular metabolism, while the vitamins are important as growth promoter and as co-enzymes [16]. These compounds present in the yeast extract solution as well as the composition of Khanna salt solution are able to supply some nutritional necessity that can not be efficiently supplied by the other solutions analyzed. In addition, the enzymatic production by IBCB 167 strain in the best condition was higher than that observed for the other strains also in the best conditions, regarding 5.3-folds higher if compared to the IBCB 384 strain.

\subsection{Optimization of Enzyme Production by CCRD}

The experimental design is an important tool to analyze the enzyme production under different culture conditions, such as SSF, allowing to study the interaction of the independent variables. Bhanu et al. (2008) [17] used the factorial design to evaluate the effect of $\mathrm{pH}$, yeast extract and mixtures of carbon sources on the production of conidia by M. anisopliae. Patel et al. (2007) [18] used a Plackett-Burman with eight independent variables for chitinase production by Paenibacillus sabina JD2. The influence of other parameters can also be evaluated as for example the cultivation period and the humidity in SSF. These parameters are determinant for fungal development and, consequently, for the enzyme production. There is an optimal range of water activity for microbial growth that should be analyzed for each species. According to Table 3, the influence of the independent variables growth' time and medium humidity on chitinase production by all four strains of $M$. anisopliae was analyzed using a $2^{\text {nd }}$-order planning. Both variables showed a positive effect on the production of extracellular chitinase for all strains (IBCB 167, 360, 384 and 425), regarding an increase in the enzymatic levels. The Pareto chart for the enzyme production by the strain IBCB 167 shows that the linear variable time of growth has a positive effect on the enzyme production, but very long periods of time already have a negative effect. The linear variable moisture shows that the addition of tap water is favorable for chitinase production, but too much water turns the production into negative. The interaction between these variables was not significant (Figure 2(a)). The CCRD performed for each strain was statistically significant with the F-value calculated higher than the F-value tabulated. The coefficient of determination $\left(\mathrm{R}^{2}\right)$, that explains the proportion of variation related to the total variation of responses, obtained with the CCRD for each strain was close to 1 . The $\mathrm{R}^{2}$ obtained for the strain IBCB 167 was 0.87 (Table 4), with $p$ value fixed at 0.1 , 
what allows the obtainment of the response surface plot (Figure 2(b)) and the equation that describes the model (Equation 1), where $\mathrm{Z}$ is the enzyme activity (U/g of substrate), $\mathrm{x}$ is the variable time of growth and $\mathrm{y}$ is the variable humidity.

$$
Z=5.36+1.63 \mathrm{x}-1.34 \mathrm{x}^{2}+1.09 \mathrm{y}-1.88 \mathrm{y}^{2}
$$

Considering the strain IBCB 360 , the $\mathrm{R}^{2}$ value was 0.89 with $p$-value fixed at 0.1 , and all variables (linear and quadratic mode) as well as the interaction between them were significant (Table 5). The respective Pareto chart (Figure 3(a)) shows that the linear variable time of growth has a positive effect on the production of chitinase, but a very long time has a negative effect as showed by the quadratic interaction. In addition, the linear variable moisture shows that the addition of tap water is favorable for chitinase production, but the excess of water becomes unfavorable. The interaction between both variables had a negative effect. The F-value calculated was four-times higher than the F-value tabulated, allowing the obtainment of the response surface plot (Figure 3(b)) and the equation that describes the model

Table 3. Total extracellular chitinase activity produced by isolates 360, 384 and 425 M. anisopliae cultured in SSF through the CCRD.

\begin{tabular}{|c|c|c|c|c|c|c|c|c|}
\hline \multirow[b]{2}{*}{ Treatments } & \multicolumn{2}{|c|}{ Coded values } & \multicolumn{2}{|c|}{ Real values } & \multicolumn{4}{|c|}{ Chitinase activity (U/g substrate) } \\
\hline & Time growth $\mathrm{X}$ & Humidity $\mathbf{Y}$ & Time growth & Humidity \% & 167 & 360 & 384 & 425 \\
\hline 1 & -1.00 & -1.00 & 5 & 30 & 0.00 & 0.00 & 0.00 & 0.04 \\
\hline 2 & 1.00 & -1.00 & 12 & 30 & 1.27 & 7.36 & 1.63 & 1.45 \\
\hline 3 & -1.00 & 1.00 & 5 & 65 & 1.14 & 3.90 & 0.72 & 4.26 \\
\hline 4 & 1.00 & 1.00 & 12 & 65 & 3.49 & 4.68 & 2.81 & 6.27 \\
\hline 5 & 0.00 & 0.00 & 9 & 48 & 5.38 & 6.18 & 4.60 & 6.38 \\
\hline 6 & 0.00 & 0.00 & 9 & 48 & 5.10 & 7.23 & 3.63 & 6.02 \\
\hline 7 & 0.00 & 0.00 & 9 & 48 & 5.59 & 6.96 & 4.51 & 5.84 \\
\hline 8 & -1.41 & 0.00 & 4 & 48 & 0.05 & 0.66 & 0.43 & 1.50 \\
\hline 9 & 1.41 & 0.00 & 13 & 48 & 6.70 & 6.12 & 2.18 & 4.50 \\
\hline 10 & 0.00 & -1.41 & 9 & 23 & 0.40 & 0.33 & 0.44 & 0.55 \\
\hline 11 & 0.00 & 1.41 & 9 & 72 & 4.17 & 6.98 & 1.29 & 3.29 \\
\hline
\end{tabular}

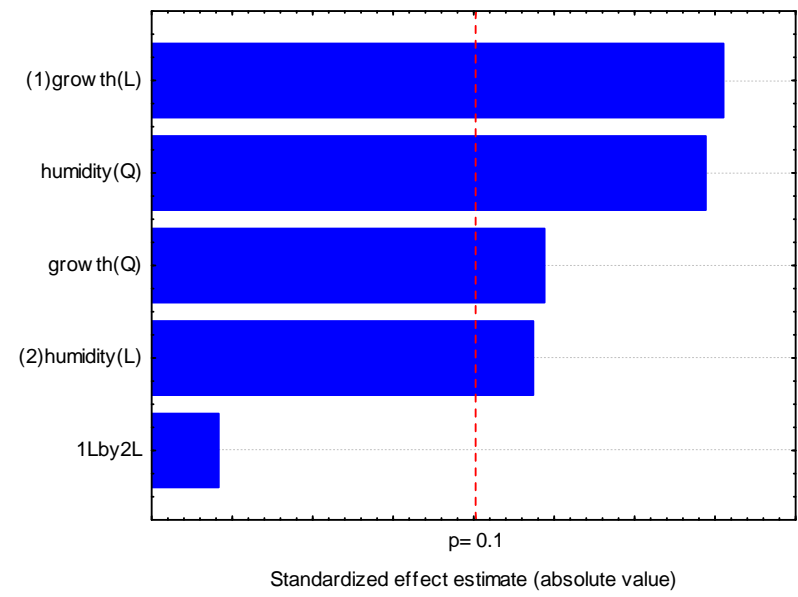

(a)

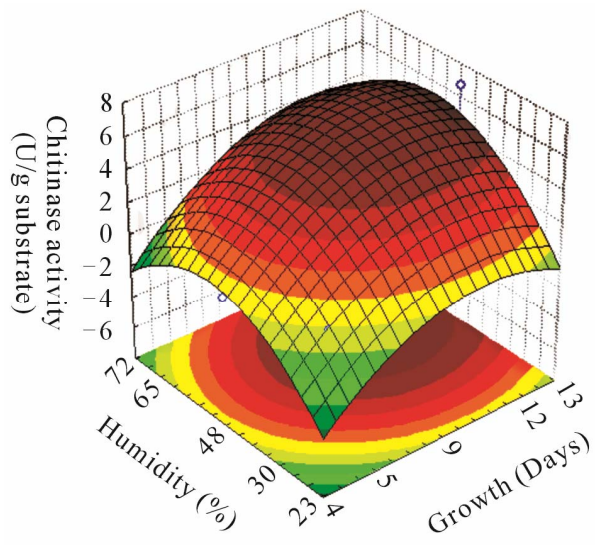

(b)

Figure 2. Pareto chart (a) and response surface plot (b) of the factorial design for the influence of the independent variable time of growth and humidity on chitinase production by M. anisopliae IBCB 167 under SSF using silkworm chrysalis as substrate. 
Table 4. Analysis of variance (ANOVA) for chitinase production isolated $167 \mathrm{M}$. anisopliae grown in SSF.

\begin{tabular}{lcccc}
\hline $\begin{array}{l}\text { Source for } \\
\text { Variation }\end{array}$ & $\begin{array}{c}\text { Sum of } \\
\text { Square }\end{array}$ & $\begin{array}{c}\text { Degrees of } \\
\text { Freedom }\end{array}$ & Mean & Square \\
\hline Regression & 54.59 & 3.00 & 18.19 & Calculated \\
Residual & 8.39 & 7.00 & 1.20 & \\
Total & 62.99 & 10.00 & & \\
\hline
\end{tabular}

Regression coefficient: $\mathrm{R}=0.87$; Ftab $0.90,3 ; 7=3.07$.

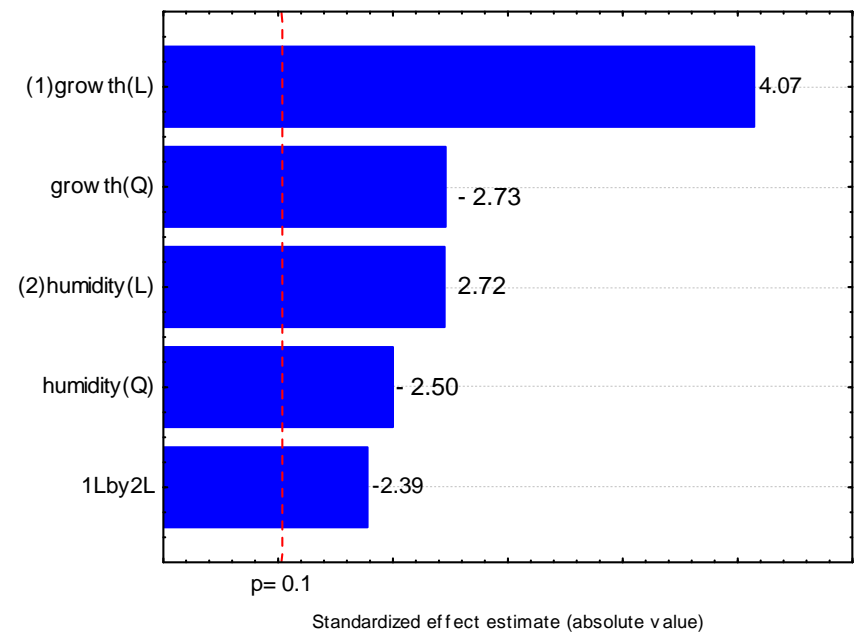

(a)
Table 5. Analysis of variance (ANOVA) for chitinase production isolated 360 M. anisopliae grown in SSF.

\begin{tabular}{lcccc}
\hline Source for & Sum of & Degrees of & Mean & F \\
Variation & Square & Freedom & Square & Calculated \\
\hline Regression & 76.50 & 4.00 & 19.13 & 12.10 \\
Residual & 9.48179 & 6.00 & 1.58 & \\
Total & 85.98456 & 10.00 & & \\
\hline
\end{tabular}

Regression coefficient: $\mathrm{R}^{2}=0.89 ;$ Ftab $0.90,3 ; 7=3.18$.

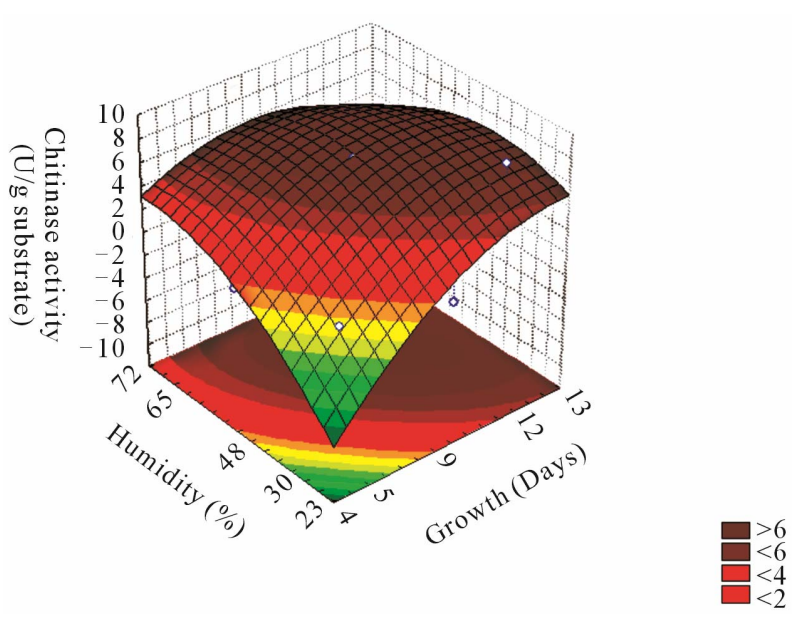

(b)

Figure 3. Pareto chart (a) and response surface plot (b) of the factorial design for the influence of the independent variable time of growth and humidity on chitinase production by M. anisopliae IBCB 360 under SSF using silkworm chrysalis as substrate.

(Equation (2)), where $\mathrm{Z}$ is the enzyme activity ( $\mathrm{U} / \mathrm{g}$ of substrate), $\mathrm{x}$ is the variable growth time and $\mathrm{y}$ is the variable humidity.

$$
Z=6.79+1.98 x-1.59 x^{2}+1.33 y-1.45 y^{2}-1.64 x y
$$

The $\mathrm{R}^{2}$ value obtained for the strain IBCB 384 was 0.97 , with $p$-value fixed at 0.1 (Table 6). The influence of all variables (linear and quadratic mode) was significant. The same can not be observed for the interaction between both variables. According to the Pareto chart (Figure 4(a)), the increase of the linear variable time of growth has a positive effect on the chitinase production, but a very long period lead to a negative effect. The linear variable humidity showed that the addition of tap water is favorable for the enzyme production, but when the humidity is excessive the production decreases. The F-value calculated was 47.55 if compared to the F-value tabulated of 3.62, what allows the obtainment of the response surface graph (Figure 4(b)) and the equation that describes the model (Equation (3)), where $\mathrm{Z}$ is the enzyme activity ( $\mathrm{U} / \mathrm{g}$ of substrate), $\mathrm{x}$ is the variable growth time and $y$ is the variable humidity.

$$
Z=4.25+0.78 \mathrm{x}-1.42 \mathrm{x}^{2}+0.39 \mathrm{y}-1.65 \mathrm{y}^{2}-0.12 \mathrm{xy}
$$

According to Table 7, the $\mathrm{R}^{2}$ value was 0.93 for the planning using the strain IBCB 425. The linear and quadratic effects for both independent variables were statistically significant with $p$-value fixed at 0.05 , but not for the interaction effect (Figure 5(a)). The linear variable time of growth had a positive effect on the production of chitinase, but long period has a negative effect as shown by the quadratic effect. The analysis of the effect of the moisture showed that the addition of tap water was favorable for chitinase production, but at high humidity environment the enzymatic production is reduced (Figure 5(a)). The F-value calculated was 9 times higher than the F-tabulated allowing the obtainment of the response surface plot (Figure 4(b)) and of the adjusted equation that describes the model (Equation (4)), where $\mathrm{Z}$ is the enzyme activity (U/g of substrate), $\mathrm{x}$ is the variable growth time and $\mathrm{y}$ is the variable humidity.

$$
Z=6.07+0.96 x-1.40 x^{2}+1.62 y-1.95 y^{2}
$$

The higher level of extracellular chitinase was ob- 
Table 6. Analysis of variance (ANOVA) for chitinase production isolated $384 \mathrm{M}$. anisopliae grown in SSF.

\begin{tabular}{lcccc}
\hline Source for & Sum of & Degrees of & Mean & F \\
Variation & Square & Freedom & Square & Calculated \\
\hline Regression & 26.76 & 3.00 & 8.92 & 47.55 \\
Residual & 0.93803 & 5.00 & 0.19 & \\
Total & 27.69867 & 10.00 & & \\
\hline
\end{tabular}

Regression coefficient: $\mathrm{R}^{2}=0.97$; Ftab $0.90,3 ; 5=3.62$.

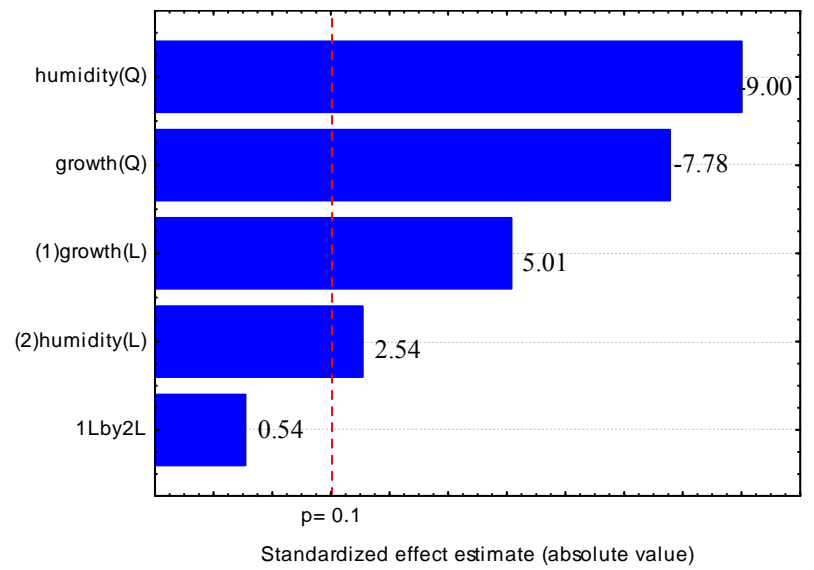

(a)

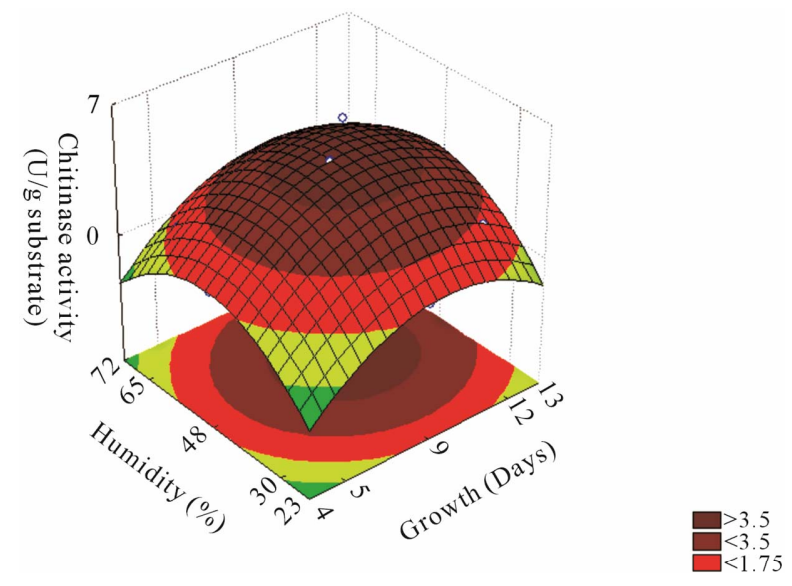

(b)

Figure 4. Pareto chart (a) and response surface plot (b) of the factorial design for the influence of the independent variable time of growth and humidity on chitinase production by M. anisopliae IBCB 384 under SSF using silkworm chrysalis as substrate.

tained with the strain IBCB 360 (7.23 U/g of substrate) with moisture ratio from $45 \%$ to $62 \%$ and incubation periods of 8 to 12-days using silkworm chrysalis as substrate according to the analysis of the surface response plot. This same ratio for both variables was also observed for the other strains analyzed. Similarly, the chitinase production by Aspergillus sp. S1-13 was increased with 58\%
Table 7. Analysis of variance (ANOVA) for chitinase production isolated $425 \mathrm{M}$. anisopliae grown in SSF.

\begin{tabular}{lcccc}
\hline Source for & Sum of & Degrees of & Mean & F \\
Variation & Square & Freedom & Square & Calculated \\
\hline Regression & 53.77 & 3.00 & 17.92 & 29.34 \\
Residual & 4.27600 & 7.00 & 0.61 & \\
Total & 58.04445 & 10.00 & & \\
\hline
\end{tabular}

Regression coefficient: $\mathrm{R}^{2}=0.93$; Ftab 0.95,3;7 = 3.07.

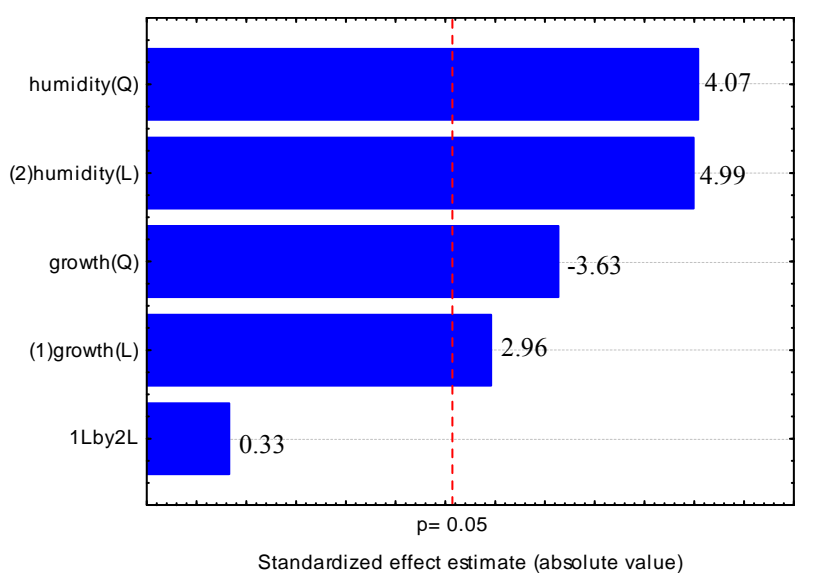

(a)

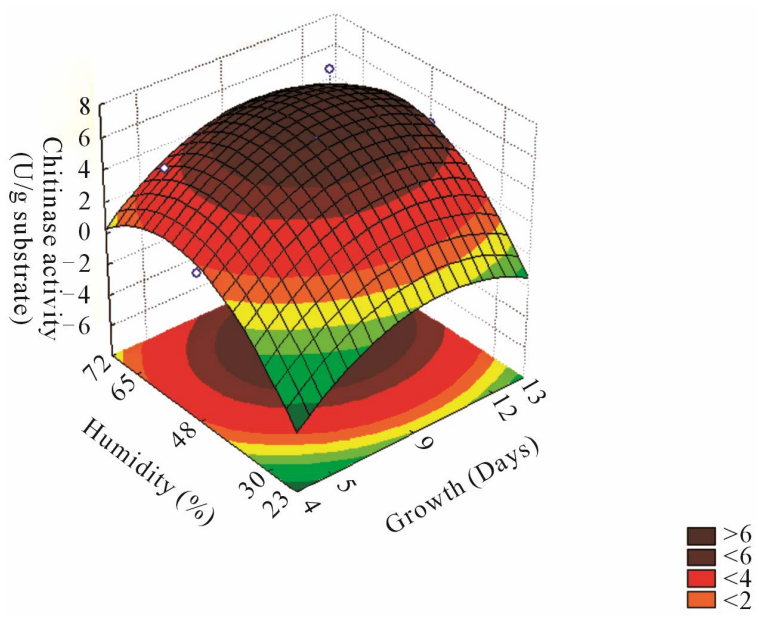

(b)

Figure 5. Pareto chart (a) and response surface plot (b) of the factorial design for the influence of the independent variable time of growth and humidity on chitinase production by M. anisopliae IBCB 425 under SSF using silkworm chrysalis as substrate.

- $65 \%$ of water under SSF using shrimp shellfish as substrate [19]. The optimization process of chitinase production using CCRD allowed an increase in chitinase production by all isolates if compared to the production showed in Table 3 . The enzyme production by the strain IBCB 167 was increased two-times under optimized 
conditions, while for the strains IBCB 360 and 425 the chitinase production was increased four-times and ninetimes for the strain IBCB 384. Despite the good enzyme production with high humidity, M. anisopliae strains were able to produce chitinases in dried conditions as well. This flexibility demonstrated by all strains is an important factor that should be considered, since the presence of water in the environment is unstable. Chitinase production by the strain IBCB 360 under optimized conditions was two times higher than that observed for the production by Trichoderma harzianum $(3.14 \mathrm{U} / \mathrm{g}$ of substrate) under SSF using a mixture of chitin and wheat bran as substrate [20]. In addition, this is the first report that shows the possibility to use chrysalis, a biological residue of the textile industry that is discarded into the environment, as substrate for chitinase production by different strains of $M$. anisopliae under SSF.

All equations obtained were validated performing experiments using 9 day-old cultures and humidity adjusted for $48 \%$. Under these conditions the enzymatic activity values experimentally obtained were 5.20, 7.07, 4.60 and $6.08 \mathrm{U} / \mathrm{g}$ of substrate for the strains IBCB 167, 360, 384 and 425 , respectively, which are in agreement with the values obtained using the equations (Equations (1)-(4)) of $5.36,6.80,4.25$ and $6.07 \mathrm{U} / \mathrm{g}$ of substrate, respectively.

There are many works which demonstrate that the enzymatic production using SSF is higher than those obtained using Submerged Fermentation. The conditions observed in SSF is much closer to the conditions found in nature by the fungus. The chitinase production in both fermentation conditions has been reported for M. anisopliae [17,21]. Usually, the conditions of the SSF are simple and the substrate used has the necessary nutrients for the growth of microorganism. The destination of the biological residues is a preoccupation around the world. These residues, such as chrysalis can be used as alternative substrates to produce enzymes, adding aggregate value to this organic residue and minimizing the negative impact in the environment. On the other hand, the use of low cost substrates has a significant advantage under economic view, reducing the production costs in the industry. Many works showing chitinase production have used colloidal chitin or crab and shrimp shell powder [22-25] as the main substrate/carbon source. Chitinase production using arthropods cuticle was also demonstrated by Da Silva et al. (2005) [4].

Chitinase, among other enzymes, from entomophatogenic fungi is related to pathogenicity and virulence. Virulence is defined as the capacity degree that the microorganisms have to cause disease [26]. The virulence of fungal strains over different arthropods is variable and it is related to the production of enzymes and other virulence factors [27]. The production of endochitinase $\mathrm{CH} 2$ by $M$. anisopliae as a virulence factor on Dysdercuspe- ruvianus was demonstrated by Boldo et al. (2009) [5]. Mustafa \& Kaur (2009) [28] also evaluated the production of extracellular enzymes from 12 strains of M. anisopliae, observing a wide variation in the production of extracellular enzymes. The extracellular lipase produced by $M$. anisopliae also participates in the process of infection [29]. The cultivation of M. anisopliae under FSbm using cuticles of Dysdercus peruvianus, Boophilus microplus and Anticarsia gemmatalis as carbon sources showed differences in the secretion of total proteins, chitinases and proteases [4]. These differences in the enzymes secretion are important as virulence factor directly related with the potential of the fungus $M$. anisopliae to recognize the structure of the cuticle of their host and to secrete the correct enzymatic pool. According to Freimoser et al. (2003) [30], M. anisopliae can encode different chitinase isoforms and other proteins as function of the material used as substrate.

The four M. anisopliae strains (IBCB 167, 360, 384 and 425) studied have been recognized according to their potential to control the pest Diatraea saccharalis promoting the death of $55 \%, 68 \%, 90 \%$ and $82 \%$, respecttively, of the insect [8]. However, the chitinase production by these strains had not been analyzed until this moment. The chitinases produced by these strains can be considered an important virulence factor. We found that the best producer of chitinase is the strain IBCB 360, what is not coincident with the best percentage of control found to $D$. saccharalis. The strain IBCB 425 was the second best chitinase producer and was able to control $90 \%$ of the pest $D$. saccharalis. The strain IBCB 167 was the third chitinase producer and did not show a good percentage of $D$. saccharalis control. Interestingly, the strain IBCB 384 was the lowest chitinase producer, but it was able to control $82 \%$ of the pest $D$. saccharalis. This is the first work that relates the production of extracellular chitinase from these strains to understand the potential capacity to control pests. It is important to highlight that the potential of virulence of an entomopathogenic fungus depends on different factors and not only of the chitinase production, what justifies the differences between the chitinase production by each strain and its capacity to control $D$. saccharalis. These strains are able to produce other virulence factors that were not quantified in this study. In addition, the use of chrysalis as substrate must induce the expression of other genes differently from that observed for the control of $D$. saccharalis. Differences in gene expression of M. anisopliae grown on cuticle or hemolymph from its host have been observed [31]. The results obtained are interesting and indicate that chitinases produced by the strains IBCB 167, 360,384 and 425 of the fungus $M$. anisopliae on chrysalis can have different degrees of participation in the infection process. 


\section{Conclusion}

All strains of the entomophatogenic fungus $M$. anisopliae showed flexibility to produce chitinases under SSF using chrysalis, which was used for the first time as substrate, indicating their potential to adapt to the environment conditions, important factor that should be considered for the infection process. Under optimized condition by CCRD, the strain IBCB 360 was the best chitinase producer although this strain is not the best controller of $D$. saccharalis, indicating that other virulence factors are also involved in the infection.

\section{Acknowledgements}

This Investigation was supported by Fundação de Apoio à Pesquisa do Estado de São Paulo (FAPESP) and Coordenadoria de Apoio ao Ensino Superior (CAPES). This manuscript is part of the CBR Doctoral (Comparative Biology Post-Graduate Program, FFCLRP, USP). We thank BRATAC S.A. and Mauricio de Oliveira for technical assistance.

\section{REFERENCES}

[1] S. B. Alves, "Controle Microbiano de Insetos," 2nd Edition, FEALQ, Piracicaba, 1998.

[2] R. J. St. Leger, P. K. Durrands, R. M. Cooper and A. K. Charnley, "Regulation of Production of Proteolytic Enzymes by Entomopathogenic Fungus Metarhizium anisopliae," Achieves of Microbiology, Vol. 150, No. 4, 1988, pp. 413-416. doi:10.1007/BF00408316

[3] S. Paris and G. Segretain, "Etude de l'activité Lipasique Esterasique Intracellulaire Beauveria tenella," Annales de Micrology, Vol. 129, 1978, pp. 71-77.

[4] M. V. Da Silva, L. Santi, C. C. Staats, A. M. Costa, E. M. Colodel, D. Driemeier, M. H. Vainstein and A. Schrank, "Cuticle-Induced Endo/Exoacting Chitinase CHIT30 from Metarhizium anisopliae Is Encoded by an Ortholog of the chi3 Gene," Research in Microbiology, Vol. 156, No. 3, 2005, pp. 382-392. doi:10.1016/j.resmic.2004.10.013

[5] J. Y. Boldo, A. Junges, K. B. Amaral, D. C. Staats, M. H. Vainstein and A. Schrank, "Endochitinase CHI2 of the Biocontrol Fungus Metarhizium anisopliae Virulence Excellent Affects toward the Cotton Stainer Bug Dysdercus peruvianus," Current Genetics, Vol. 55, No. 5, 2009, pp. 551-560. doi:10.1007/s00294-009-0267-5

[6] P. A. Shah and J. K. Pell, "Entomopathogenic Fungi as Biological Control Agents," Applied Microbiology Biotechnology, Vol. 61, 2003, pp. 413-423.

[7] F. V. Vega, "Insect pathology and Fungal Endophytes," Journal of Invertebrate Pathology, Vol. 98, No. 3, 2008, pp. 277-279. doi:10.1016/j.jip.2008.01.008

[8] L. O. Zappelini, "Selection of Isolates of the Entomopathogenic Fungi Beauveria bassiana and Metarhizium anisopliae for the Control of Sugarcane Borer-Cane, Diatraea saccharalis (Lepidoptera: Crambidae)," Master
Dissertation, Biological Institute, Campinas, São Paulo, 2009.

[9] L. F. Fleuri and H. Sato, "Production, Purification, Cloning and Application of Lytic Enzymes," Quimica Nova, Vol. 28, No. 5, 2005, pp. 871-879. doi:10.1590/S0100-40422005000500026

[10] R. S. Patil, V. Ghormade and M. V. Deshpande, "Chitinolytic Enzymes: An Exploration," Enzyme and Microbial Technology, Vol. 26, No. 7, 2000, pp. 473-483. doi:10.1016/S0141-0229(00)00134-4

[11] L. Duo-Chuan, "Review of Fungal Chitinases," Mycopathology, Vol. 161, No. 6, 2006, pp. 345-360. doi:10.1007/s11046-006-0024-y

[12] D. M. F. Van Aalten, D. Komander, B. Systand, S. Gaseidnes, M. G. Peter and V. G. H. Eijsink, "Structural Insights into the Catalytic Mechanism of a Family 18 Exochitinase," Proceedings of the National of Sciences Academy, Vol. 98, No. 16, 2011, pp. 8979-8984. doi:10.1073/pnas. 151103798

[13] A. C. S. Rizzatti, J. A. Jorge, H. F. Terenzi, C. G. V. Rechia and M. L. T. M. Polizeli, "Purification and Properties of a ThermosTable Extracellular $\beta$-D-Xylosidase Produced by Thermotolerant Aspergillus phoenicis," Journal of Industrial Microbiology and Biotechnology, Vol. 26, No. 3, 2001, pp. 156-160. doi:10.1038/sj.jim.7000107

[14] P. Khanna, S. S. Sundari and N. J. Kumar, "Production, Isolation and Partial Purification of Xylanase from $A s$ pergillus sp.," World Journal of Microbiology and Biotechnology, Vol. 11, No. 2, 1995, pp. 242-243. doi:10.1007/BF00704661

[15] E. A. Yamada, I. D. Alvim, M. C. C. Santucci and V. C. Sgarbieri, "Composição Centesimal e Valor Protéico de Levedura Residual da Fermentação Etanólica e de seus Derivados," Revista de Nutrição Campinas, Vol. 16, 2003, pp. 423-432.

[16] E. Espósito and J. L. Azevedo, "Fungos: Uma Introdução à Biologia, Bioquímica e Biotecnologia," Editora da Universidade de Caxias do Sul, Brazil, 2004.

[17] P. G. V. S. Bhanu, V. Padmaja and R. R. S. Kiran, "Statistical Optimization of Process Variables for the LargeScale Production of Metarhizium anisopliae Conidiospores in Solid-State Fermentation," Bioresource Technolology, Vol. 99, No. 6, 2008, pp. 1530-1537. doi:10.1016/j.biortech.2007.04.031

[18] B. Patel, V. Gohel and B. Raol, "Statistical Optimization of Medium Components for Chitinase Production by Paenibacillus sabina Strain JD2," Annals of Microbiology, Vol. 57, No. 4, 2007, pp. 589-597. doi:10.1007/BF03175360

[19] N. Rattanakit, A. Plikomol, S. Yano, M. Wakayama and T. Tachiki, "Utilization of Shrimp Shellfish Waste as a Substrate for Solid-State Cultivation of Aspergillus sp. S1-13: Evaluation of a Culture Based on Chitinase Formation Which Is Necessary for Chitin-Assimilation," Journal of Biosciense and Bioengineering, Vol. 93, 2002, pp. 550-556.

[20] M. Nampoothiri, T. V. Baiju, C. Sandhya, A. Sabu, G. Szakacs and A. Pandey, "Process Optimization for Anti- 
fungal Chitinase Production by Trichoderma harzianum," Process Biochemistry, Vol. 39, No. 11, 2004, pp. 15831590. doi:10.1016/S0032-9592(03)00282-6

[21] G. U. L. Braga, C. L. Messiah and R. Vencovsky, "Estimates of Genetic Parameters Related to Chitinase Production by the Entomopathogenic Fungus Metarhizium anisopliae," Genetics and Molecular Biology, Vol. 21, No. 2, 1998, pp. 171-177. doi:10.1590/S1415-47571998000200001

[22] L. F. Fleuri, H. Y. Kawaguti and H. H. Sato, "Production and Application of Extracellular Chitinase from Cellulosimicrobium cellulans," Brazilian Journal of Microbiology, Vol. 40, No. 3, 2009, pp. 623-630. doi:10.1590/S1517-83822009000300026

[23] R. F. Guo, B. S. Shi, D. C. Li, W. Ma and Q. Wei, "Purification and Characterization of a Novel ThermosTable chitinase from Thermomyces lanuginosus SY2 and Cloning of Its Encoding Gene," Agriculture Science, Vol. 7, 2008, pp. 1458-1465.

[24] S. R. Waghmare and J. S. Ghosh, "Study of Thermostable Chitinases from Oerskovia xanthineolytica NCIM 2839," Applied Microbiology and Biotechnology, Vol. 86, No. 6, 2010, pp. 1849-1856. doi:10.1007/s00253-009-2432-7

[25] C. Wang, M. A. Typas and T. M. Butt, "Detection and Characterization of pr 1 Virulent Gene Deficiencies in the Insect Pathogenic Fungus Metarhizium anisopliae," FEMS Microbiology Letters, Vol. 231, 2002, pp. 252-255.

[26] M. J. J. Pelczar, E. C. S. Chan and N. R. Krieg, "Microbiologia: Conceitos e Aplicações," 2nd Edition, Markron
Books, New York, 1996.

[27] M. J. Bidochka and G. G. Khachatourians, "Identification of Beauveria bassiana Extracellular Protease as a Virulence Factor in Pathogenicity toward the Migratory Grasshopper, Melanoplus sanguinipes," Journal of Invertebrate Pathology, Vol. 56, No. 3, 1990, pp. 362-370. doi:10.1016/0022-2011(90)90123-N

[28] U. Mustafa and G. Kaur, "Extracellular Enzyme Production in Metarhizium anisopliae Isolates," Folia Microbiologica, Vol. 54, No. 6, 2009, pp. 499-504. doi:10.1007/s12223-009-0071-0

[29] W. O. B. Silva, S. Mitidieri, A. Schrank and M. H. Vainstein, "Production and Extraction of an Extracellular Lipase from the Entomopathogenic Fungus Metarhizium anisopliae," Process Biochemistry, Vol. 40, No. 1, 2005, pp. 321-326. doi:10.1016/j.procbio.2004.01.005

[30] F. M. Freimoser, S. E. Screen, S. Baga, G. Hu and R. J. St. Leger, "Expressed Sequence Tag (ETS) Analysis of Two Subspecies of Metarhizium anisopliae Reveals a Plethora of Secreted Proteins with Potential Activity in Insect Host," Microbiology, Vol. 149, No. 1, 2003, pp. 239-247. doi:10.1099/mic.0.25761-0

[31] C. Wang and R. J. St. Leger, "Developmental and Transcription Responses to Host and No Host Cuticles by the Specific Locust Pathogen Metarhizium anisopliae var. acridum," Eukaryotic Cell, Vol. 4, No. 5, 2005, pp. 937947. doi:10.1128/EC.4.5.937-947.2005 